\title{
Opening science: towards an agenda of open science in academia and industry
}

\author{
Sascha Friesike • Bastian Widenmayer • Oliver Gassmann • \\ Thomas Schildhauer
}

Published online: 25 November 2014

(C) The Author(s) 2014. This article is published with open access at Springerlink.com

\begin{abstract}
The shift towards open innovation has substantially changed the academic and practical understanding of corporate innovation. While academic studies on open innovation are burgeoning, most research on the topic focuses on the later phases of the innovation process. So far, the impact and implications of the general tendency towards more openness in academic and industrial science at the very front-end of the innovation process have been mostly neglected. Our paper presents a conceptualization of this open science as a new research paradigm. Based on empirical data and current literature, we analyze the phenomenon and propose four perspectives of open science. Furthermore, we outline current trends and propose directions for future developments.
\end{abstract}

Keywords Open science $\cdot$ Research management $\cdot$ Science $\cdot$ Open innovation

JEL Classification $\mathrm{O} 31 \cdot \mathrm{O} 32 \cdot \mathrm{O} 33$

S. Friesike $(\bowtie) \cdot T$. Schildhauer

Alexander von Humboldt Institute for Internet and Society, Berlin, Germany

e-mail: friesike@ hiig.de

T. Schildhauer

e-mail: schildhauer@hiig.de

S. Friesike

University of Wuerzburg, Würzburg, Germany

B. Widenmayer

Bystronic Laser AG, Niederönz, Switzerland

e-mail: bastian.widenmayer@bystronic.com

O. Gassmann

Institute of Technology Management, University of St. Gallen, St. Gallen, Switzerland

e-mail: oliver.gassmann@unisg.ch 


\section{Introduction}

For centuries, science has been based on an open process of creating and sharing knowledge. Over time however, the quantity, quality, and speed of scientific output have changed, as has the openness of science. In the days of Galileo, scientists had to use anagrams to hide from inquisition. Later, scientists used letters to distribute their knowledge amongst colleagues. When in 1665 'Philosophical Transactions' was founded, scientists began to send their insights to scientific journals. In the last century, the number of scientific journals exploded. At the same time knowledge diffusion slowed down. In some fields the peer review process takes several years from first submission to final publication (Björk and Solomon 2013). New IT-based submission and paper tracking platforms hardly improved review times, as reviewers remain to be the bottleneck. Today, more and more academic institutions open up science by employing open access journals, sharing research data, or including others into the research process. But also large firms like Siemens, IBM, or Tesla are part of the open science phenomenon. Instead of patenting knowledge, they publish large parts of their research in order to participate in the scientific community. In doing so they mark findings as state-of-the-art and thus prevent others from patenting them.

Despite recent trends, management scholars have mostly neglected the phenomenon of open science. That is surprising as there is a clear link between the activities in the field of open science and those in the field of open innovation. Science has the purpose of developing a knowledge domain by adding theoretical or empirical insights, whereas innovation has the purpose of developing and bringing to market new offerings such as products or services. The most widely used definition of open science stems from Nielsen (2011): "Open science is the idea that scientific knowledge of all kinds should be openly shared as early as is practical in the discovery process." Open innovation by contrast is defined as "the use of purposive inflows and outflows of knowledge to accelerate internal innovation, and expand the markets for external use of innovation, respectively. [This paradigm] assumes that firms can and should use external ideas as well as internal ideas, and internal and external paths to market, as they look to advance their technology" (Chesbrough 2006, p. 1). Both definitions have the acceleration of a process by sharing knowledge in common. Many scientific findings are later turned into innovations. It is therefore desirable to understand the link between open science and open innovation as the definitions suggest that open science can lead to open innovation.

Current literature on open innovation is predominantly underlying a business-centric view. This view assumes a firm to be mainly motivated by profits. Numerous studies investigated how external ideas are utilized inside companies in order to develop new product offerings (Dahlander and Gann 2010). Additionally, scholars analyzed the possibilities of commercializing internally generated knowledge in form of intellectual property (IP) for profit generation outside the company boundaries (Chesbrough 2003a, b). Research is understood as an enabler to come to new knowledge (Koen et al. 2001). Yet, the very early stages of research and science have hardly been analyzed by the current open innovation literature. In other words, we currently experience a vibrant debate within scientific theory that focuses on open science (Bartling and Friesike 2014; Jong and Slavova 2014). Yet, this debate mostly neglects its interdependency to innovation.

This article provides a conventionalization of open science based on a literature review and semi-structured interviews with CTOs, research managers, open innovation directors, open access leaders, industrial researchers, and scientists. The paper is structured as follows: In the next section (Sect. 2), we review the literature on open innovation and open science to derive similarities and difference between both concepts. In Sect. 3, we describe 
our methodological approach before (in Sect. 4) we analyze and discuss current trends based on empirical insights. The paper concludes by providing implications and suggestions for future research (Sect. 5).

\section{Background}

\subsection{Research streams in open innovation}

The failure of large industrial research labs to drive scientific advancements towards value generation in the early 1980s manifested an anomaly that changed the rules of innovation. Shortly after its foundation in 1984, Cisco started with its open R\&D strategy, which ended up in outcompeting the world's largest R\&D center, the AT\&T's Bell labs. In the Kuhnian sense (1962), this marked a paradigm shift in innovation management. Since then, the practical and academic community called for more open models of innovation (e.g., Chesbrough 2003a, b; Christensen et al. 2005).

Within the last decade of academic research, several special issues on open innovation underpinned a fundamental change in the perception of innovation (see e.g., $R \& D$ Management 2006, 2009, 2010, and the International Journal of Technology Management 2010). This has been complemented by some special issues on open source software development as a subfield of open innovation (see e.g., Research Policy 2003, Management Science 2006). This sustainable attention of practitioners and researchers shows that open innovation has gone far beyond being a short-term fashion or hype. Within the field of open innovation the following seven research streams can be summarized:

(1) Integration of external cooperation partners along the value chain. Downstream the value chain, von Hippel's (1986) works on lead user integration highlight the virtue of user collaboration for radical innovation. Numerous studies investigated user characteristics and their impact on the degree of innovativeness, the modality of user integration, and user's motivation to collaborate (Bilgram et al. 2008; Franke et al. 2006; Luethje 2004). The phenomenon of free revealing and the fact that the user is the only external collaboration partner with use-experience makes the user a very valuable partner (Nambisan and Baron 2010; von Hippel and von Krogh 2006). Upstream the value chain, research emphasized the importance of supplier integration. The integration of suppliers into the development process at a very early stage can significantly increase innovation performance in most industries (Hagedoorn 1993).

(2) Partnering and alliances. Strong specialization necessitated the need for many companies to collaborate with partner companies from the same or other industries (Hagedoorn 2002; Schildhauer 2011). Especially, the phenomena of cross industry innovation and innovating with non-suppliers was investigated (Howells 2008; Herstatt and Kalogerakis 2005). Also established engineering firms take the role of innovation intermediaries moderating open innovation activities between collaborators (Howells 2006). This indirect opening up of the innovation process is leveraging the cross-industry innovation process, not only in traditional R\&D outsourcing modes but also in strategic innovation partnering.

(3) Open innovation processes. Open innovation can be subdivided in three core processes: outside-in, inside-out, and coupled. This classification provides guidance on how to complement and extend the internal innovation process by an external 
periphery (Gassmann and Enkel 2004). Most large companies such as Siemens and BASF started to developed detailed firm specific open innovation processes. In addition some companies such as Procter \& Gamble and Siemens assigned process owners with special positions and titles for open innovation within their corporations. In both corporations these directors attract considerable attention within the company.

(4) Open innovation tools. As a means to implement open innovation numerous tools emerged; most of them support the integration of external innovation sources (West and Lakhani 2008). Crowdsouring platforms like InnoCentive, 99design, Jovoto, Nine Sigma, or Atizo bring together solution seekers and problem solvers (Bullinger et al. 2010; Sieg et al. 2010; Dahlander et al. 2008). Thereby, they generate a virtual market place for innovative ideas and problem solutions. Toolkits for masscustomization allow an adaptation of design and product features according to customer preferences based on an iterative creation process (Piller and Walcher 2006). Community based innovation enables companies to use blogs and discussion forums to communicate with a mass of stakeholders outside the company.

(5) Open trade of intellectual property. The times where IP was solely used as a means to secure the firm's freedom to operate are over. The more open approach towards IP changed its role and importance within the firm's value creation processes (Pisano 2006). The active use of IP for in- and out-licensing unfolded new business models, which are widely discussed in literature. New phenomena like patent funds, patent trolls and patent donations emerged in recent years and increasingly attracted scientific research (Reitzig et al. 2007; Ziegler et al. 2014). At the moment, there is an ongoing debate amongst policy makers in the European Union whether a financial market for IP should be created. Policy makers in favor of new modes of technology transfer as well as financial institutions interested in new product categories are predominantly driving that process.

(6) Open business models. The paradigm of open innovation impacted business models in a sense where open innovation becomes an integral part of value creation. The integration of business model thinking in the virtue of open innovation seems to be crucial (Chesbrough 2006; Kim and Mauborgne 2004). Since the appearance of thousands of open source software initiatives under idealistic perspectives (e.g., Eric Raymond's famous 'The Cathedral and the Bazaar'), open innovation seemed to be often non-commercial. But the business model judges whether value cannot only be created but also captured. For instance in the cases of Linux or Apache many commercially successful service businesses have been developed around the open source model.

(7) Open innovation culture. Overcoming the not-invented-here syndrome (Katz and Allen 1982) presents one of the core challenges in open innovation. Studies like Herzog's (2011) revealed determinants of an open innovation culture and its impact on corporate culture, communication, and incentive systems. Companies like $3 \mathrm{M}$ or Procter \& Gamble started to integrate open innovation as a fundamental part of their corporate culture. In the case of $3 \mathrm{M}$, the degree of how much outside-in thinking is encouraged became a central pillar in leadership evaluation.

The overview on the existing research streams in the field of open innovation shows the strong application and commercialization focus of the present literature. But, detailed insights on collaboration and openness in the field of knowledge creation and science are lacking. 


\subsection{Perspectives of open science}

In the context of academic and industrial science, the sharing and combination of information is regarded as the core process of knowledge creation (Thursby et al. 2009). As scientific problems are getting more specialized and complex at the same time, it is not surprising that collaboration in science and research expanded in various disciplines within the last decades. For example in sociology, the percentage of co-authored articles almost quintupled in the last 70 years (Hunter and Leahey 2008). Comparable trends were observed in political science (Fisher et al. 1998), physics (Braun et al. 1992), and economics (Maske et al. 2003). Studies even show that authors with a high h-index are those who collaborate widely with others, form strong alliances, and are less likely to be bonded to a certain in-group (Pike 2010; Tacke 2010).

According to Merton (1973), the principle of openness has always been an integral part within the academic community. This openness is rooted in a reward system that the first person to contribute new findings to the scientific community receives in return various forms of recognition (Stephan 1996; McCain 1991; Hagström 1965). However, new communication technologies enable academic science to be even 'more open', which led to the term open science. Here, open has to be seen in contrast to the prior status quo (e.g., a publication was available only to the subscriber of a journal and only after it was published) and not in contrast to 'closed science'. Contradictory, industrial scientists were perceived as being much more concerned about confidentiality as a means to secure future returns on R\&D investments (Cohen et al. 2000). Recent studies however indicate that this disparity seems to diminish as increasingly cross-institutional bonds emerged (Murray 2006; Powell et al. 2005). For example, Haeussler (2011) found that for both academic and industrial scientists the likelihood of collaboration and exchange depends on the competitive value of the requested information and on the degree to which the researcher's community conforms to the 'norm of open science' (Rhoten and Powell 2007). Differences between academic and industrial research become blurred (Vallas and Kleinman 2008). Thus, academic and industrial science moved from a "binary system of public vs. proprietary science to [...] arrangements which combine elements of both" (Rhoten and Powell 2007, p. 346). The convergence of academic and industrial science and the increasing importance of collaboration and openness drive the need to gain more insight in how open science is characterized.

On the basis of relevant literature, we developed a framework of four perspectives in order to analyze initiatives and trends in the field of open science. This framework incorporates the various elements of open science that are derived from the following literature streams: open source (e.g., Von Krogh and von Hippel 2003), alliance and partnership (e.g., Howells 2008; Herstatt and Kalogerakis 2005), open science (e.g., Bartling and Friesike 2014; De Roure et al. 2010; Grand et al. 2012; Gowers and Nielsen 2009; Haeussler 2011; Jong and Slavova 2014; Lievrouw 2010; Meyer and Schroeder 2013; Mukherjee and Stern 2009; Neylon and Wu 2009; Nielsen 2012; Procter et al. 2010; Scheliga and Friesike 2014; Tacke 2010; Waldrop 2008), and open innovation (e.g., Chesbrough 2003a, 2003b, 2006; Dahlander and Gann, 2010; van de Vrande et al. 2010).

Actors in open science include institutions such as universities and corporations as well as individual researchers. From a value chain perspective, open science includes the very front-end activities of basic science, applied science, and applied research. Despite the contextual backgrounds of academia and industry, research is rather driven by curiosity, reputation, and acknowledgement than by profit and applied oriented thinking. We differentiate four perspectives of open science: 
(1) Philanthropic perspective. Doing research requires infrastructural and content-related elements whose access has been predominantly restricted. Current trends foster a democratization of science and research in the sense of distributing scientific content, tools, and infrastructures freely. Many universities started to offer public lectures or courses with the goal in mind to bring science and research closer to society and to market scientific findings. Most of the public lectures are streamed online and thus are globally available (Tacke 2010). Additionally, this trend includes the rise of open access journals that provide users with the non-restricted right to read, download, copy, distribute, print, search, or link to the full texts of articles. As most traditional journals generate revenues based on subscriptions, the majority of open access journals are funded by the authors through publication fees. Within the last years, the visibility and prominence of open access journals significantly increased due to the growing numbers and the establishment of the Directory of Open Access Journals.

(2) Reflationary perspective. Currently, we witness a trend towards making scientific results freely available during pre-publication. Knowledge is shared in a very early stage within the research process. Motives to do so are manifold. Researchers are able to reflect first thoughts, to promulgate preliminary scientific results, and to promote new ideas within the scientific community. Thereby, they signal tacit knowledge and reputation that might attract other researchers and institutions (Hicks 1995). Furthermore, they are capable of actively influencing future research directions and starting new scientific discussions. Colleagues and amateurs are invited to give feedback and to join in for collaborative knowledge creation. External involvement diminishes problems with respect to local search bias and groupthink many closed scientific research teams suffer from. At the same time the journals and publishers have a self-interest in pre-publications: Papers which have been published before being printed will get cited more often and therefore increase the citation impact and thus attractiveness of the journal. Moreover, the memory and transparency of the World Wide Web allows tracing thoughts and knowledge creation. This minimizes the risk of lost authorship. Comments and evaluations of peers might give guidance in research phases of high uncertainty.

(3) Constructivistic perspective. The opening of science and research enables new collaborative forms of knowledge creation. This knowledge creation does not only bring new knowledge into being but also new opportunities for new user models and new businesses. Crowdsourcing is one prominent example: Problem seekers pull for new scientific solutions by broadcasting problems to an unknown mass of potential problem solvers. Virtual rooms are used as an exchange platform where problem seekers and solvers can interact. Small groups form virtual exchange platforms for loose or moderated exchange with the goal of knowledge creation. Open platforms typically address several fields in a more interdisciplinary manner than the typical disciplinary mainstream journals. The integration of more than one scientific discipline under one roof fosters cross-fertilization of researchers and scientists. This interdisciplinary approach enhances technology fusions and the generation of innovative solutions (Kodama 1992).

(4) Exploitative perspective. Most researchers are oriented towards the generation of novel scientific findings neglecting real life application. The active sharing and promoting of scientific knowledge enables researchers to close this gap towards application-oriented knowledge exploitation faster. In cooperation with practitioners a common shared construction of new artifacts based on the latest scientific findings is possible. 
The Following table provides an overview on open science initiatives with respect to the four just discussed perspectives (Table 1).

\section{Methodology}

Given the young nature of the phenomenon, our empirical research mainly relies on a qualitative exploratory research approach based on interviews, Internet research, and document analysis. This triangulated qualitative approach is an appropriate means to navigate unclear boundaries between phenomenon and context in the early stages of research. Our data generally relies on the primary source of semi-structured expert interviews and secondary source of company press releases and Internet research. Between 2008 and 2011, we conducted 38 interviews with different actors in technology intensive industry and academic research, namely CTOs, R\&D managers, open innovation directors, senior industry and academic researchers, directors of research institutes, editors and referees of academic journals, and university presidents. This kind of triangulation allows us to minimize the bias of personal perspective and enhance the validity of the information.

At the outset of our interviewee sampling, we scanned our personal contacts, websites of research institutions, research databases, and the public press to identify experts in the field of open science that were most promising in revealing new insights. Our goal was to generate a heterogeneous sample that allowed us to analyze open science from various different viewpoints and validate our results. After each interview, we asked our respondents to name further colleagues who may reveal more insights applying a snowball sampling. No further interviews were conducted when we achieved theoretical saturation and the interviewees did not reveal new empirical insights.

The framework described in chapter 2.3 guided our data acquisition and data analysis. Based on the framework we developed an interview guideline, which we adapted according to new empirical insights that emerged during the research process. Thus, our field data was collected and analyzed iteratively based on reflection of scientific literature. This led to alternations between inductive and deductive procedures (Eisenhardt 1989). To combine the advantages of unstructured and semi-structured interview methods, we started with open-ended questions, followed by a structured questionnaire protocol. Besides asking formal questions regarding the institutions' motivations and barriers of opening up science, the interviewees were also strongly encouraged to provide related examples from their daily business, including current research projects. The intention of the interviews was to identify drivers, inhibitors and current trends in open science and research.

The data was primarily collected by personal face-to-face or telephone interviews, which lasted between 40 and $120 \mathrm{~min}$ on average. Each interview was transcribed. The transcripts were transferred into an excel tool to break the interviews down into single statements. Each statement was paraphrased and grouped into categories. The identified trends emerged out of the categories. Two researchers independently analyzed the data allowing cross comparisons that increased the validity of the results.

Academic research representatives of the following institutes were interviewed: Berkeley University, European Organization for Nuclear Research (CERN), ETH Zurich, Research Center Jülich, RWTH Aachen University, Stanford University, Swiss Commission for Technology and Innovation (CTI), Swiss Federal Laboratories for Materials Science and Technology (EMPA), Technical University Dortmund, Technical University Munich, University of Manchester, University of Cologne, University of St. Gallen. From 


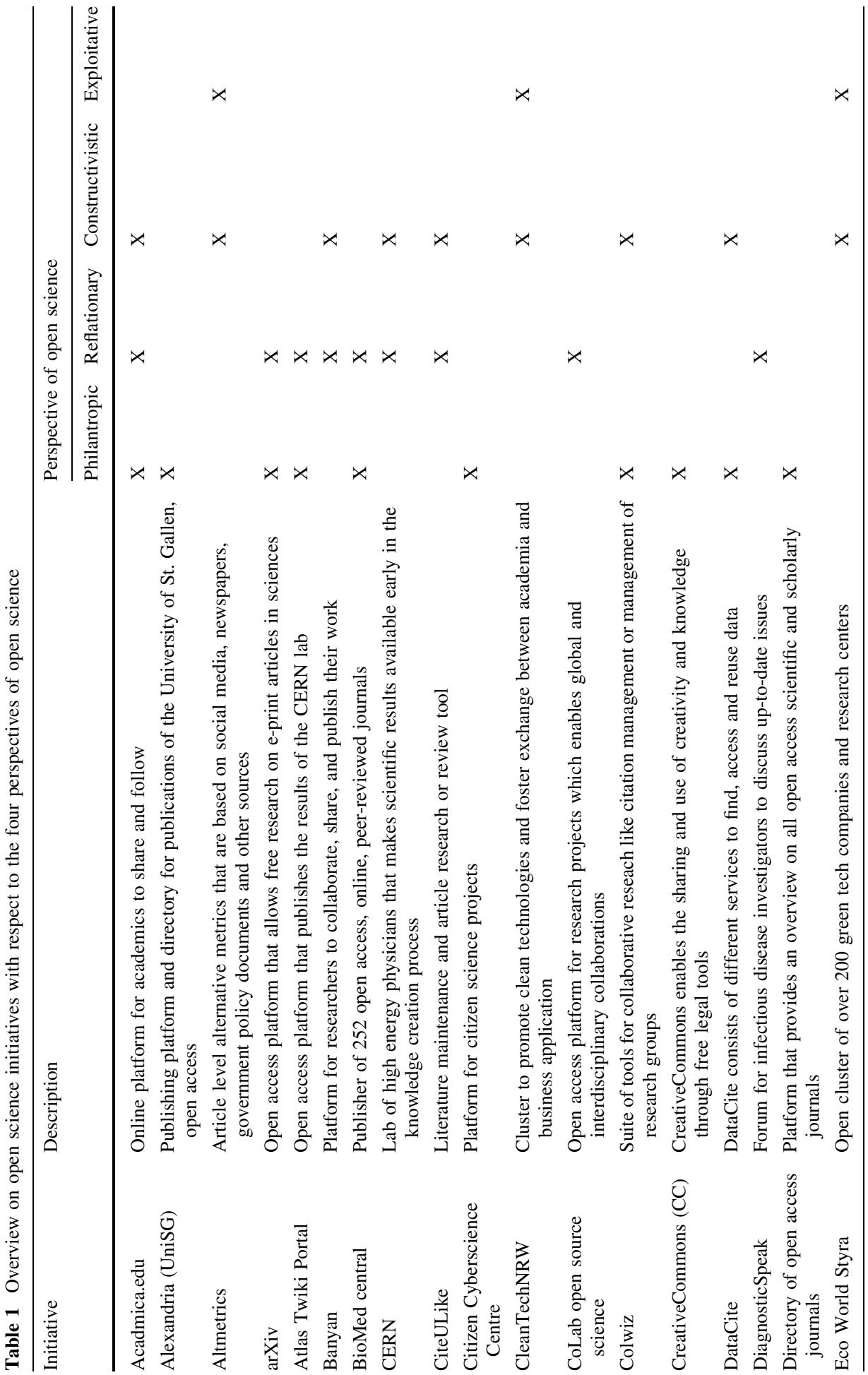




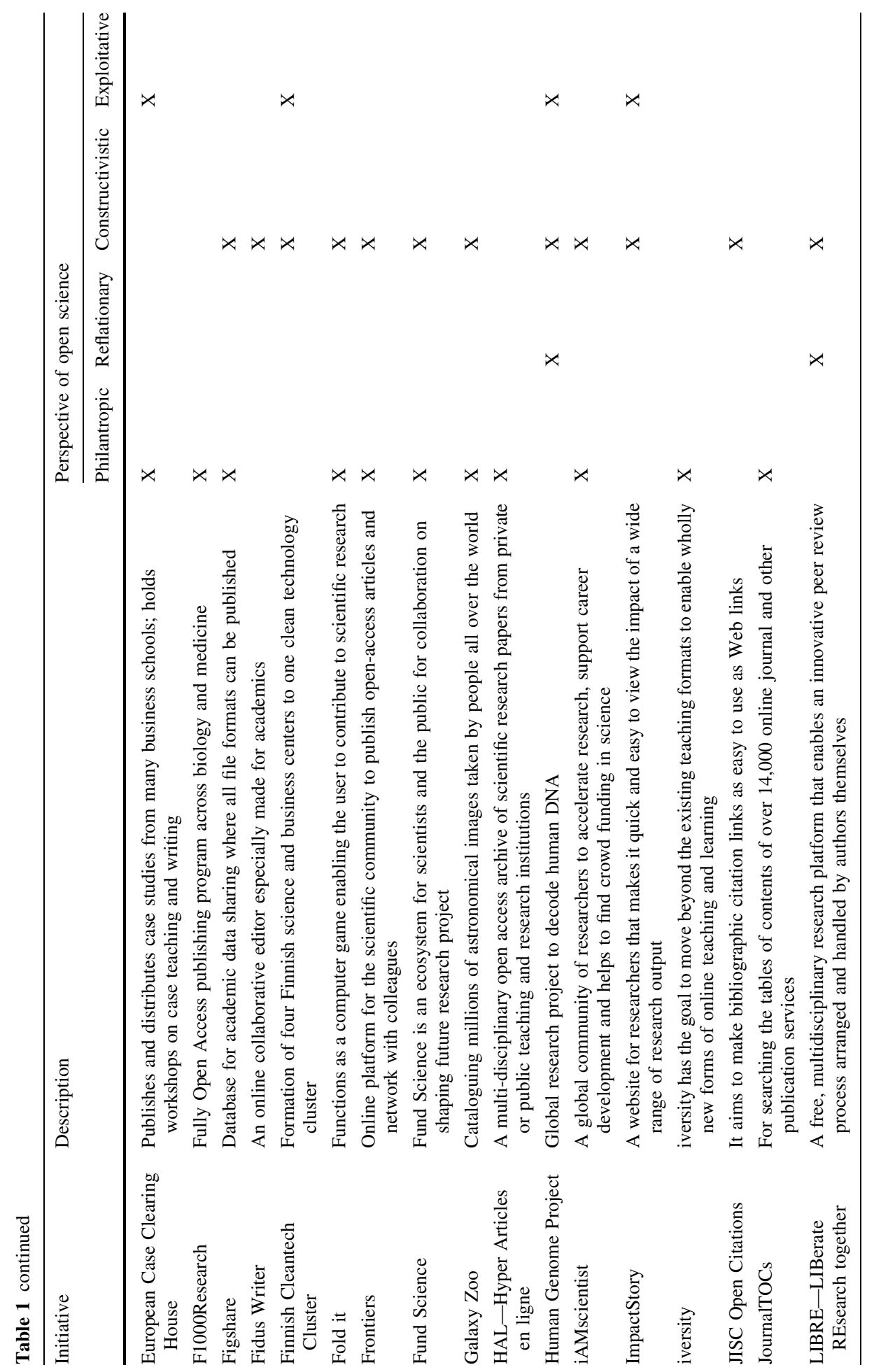




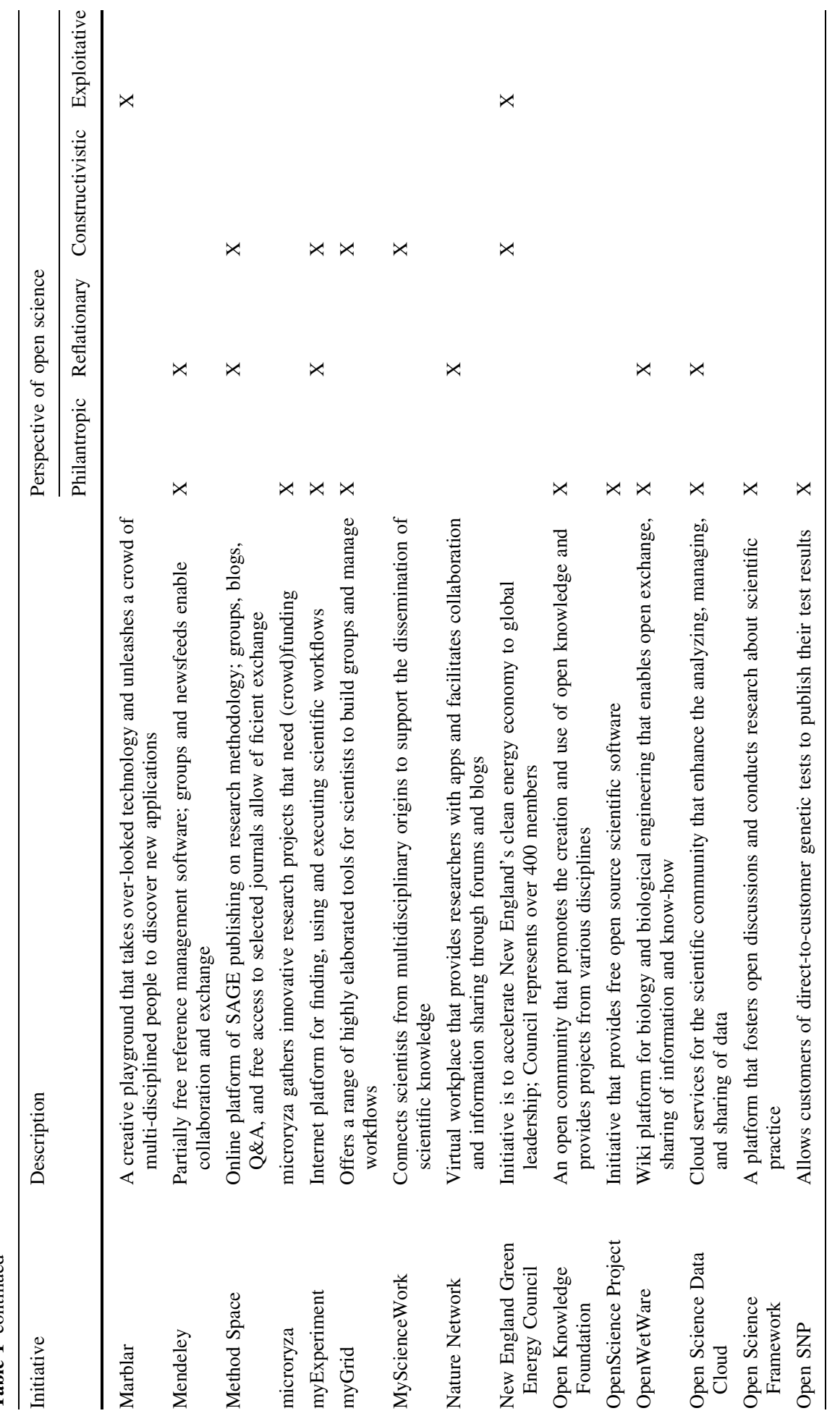




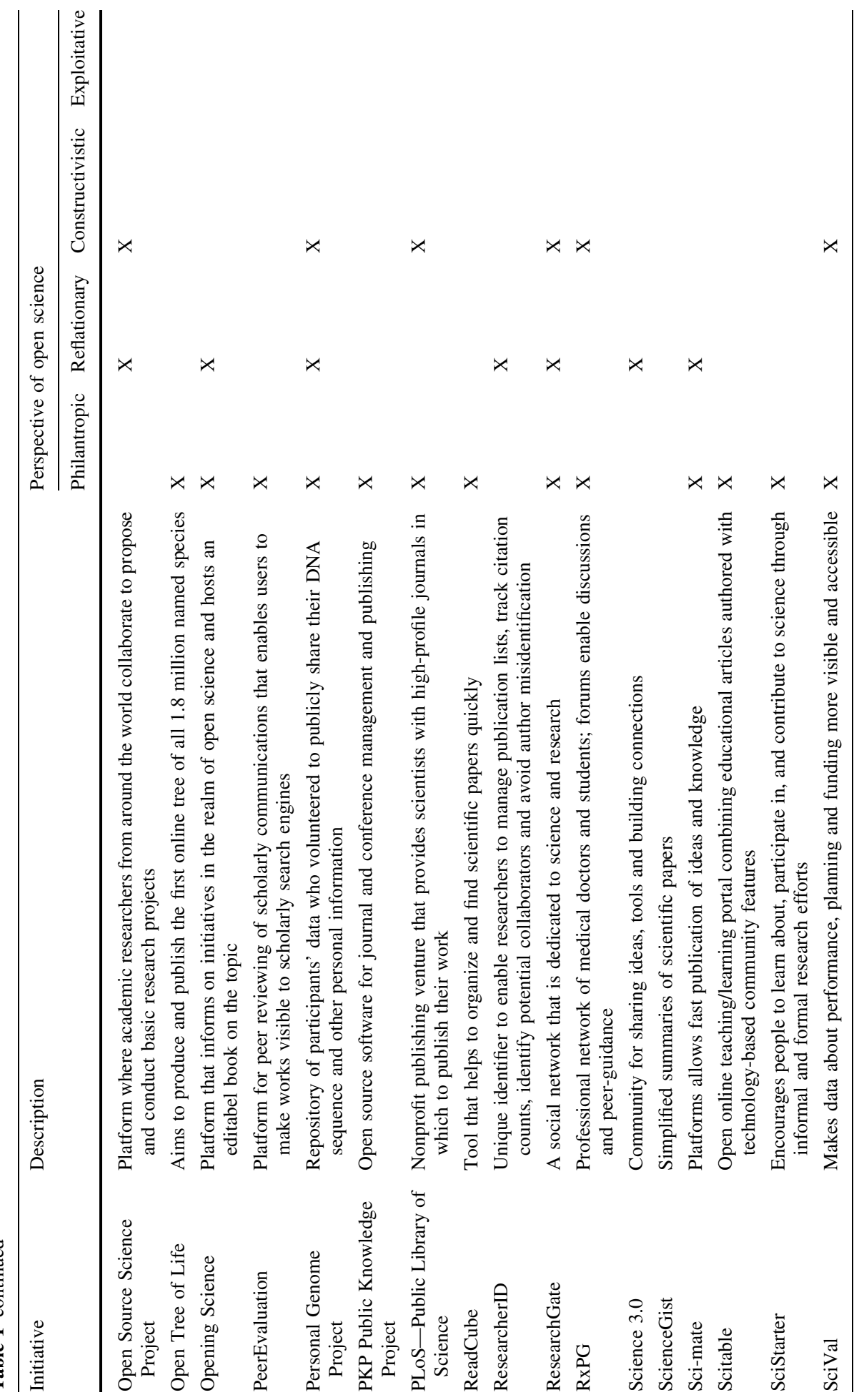




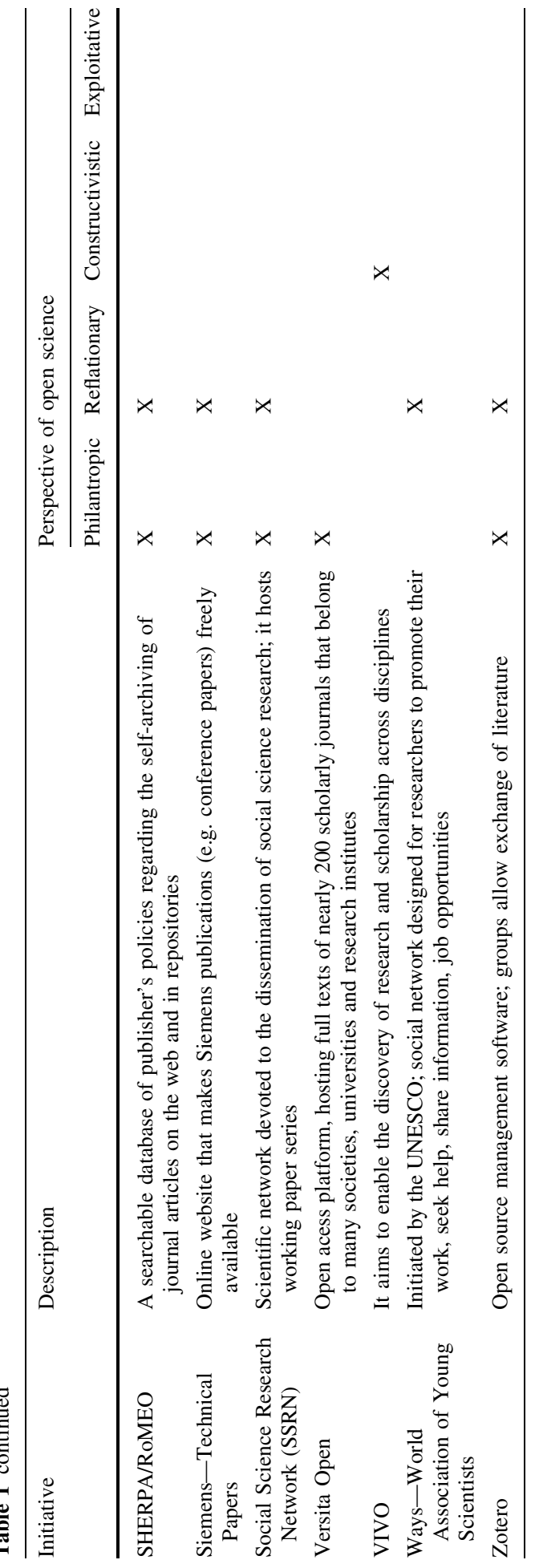


industry, the following companies were included: ABB, Bayer, Daimler, Henkel, IBM, Microsoft, Nestlé, Novartis, Procter \& Gamble, SAP, Schindler, and Siemens.

In early 2013 we conducted a second field phase and carried out 22 further interviews with experts in the realm of open science. These interviews were mainly conducted to gain insights into how individual researchers deal with the challenges in open science (e.g., open access journals make publications widely available but a researcher's career is not based on availability of research results but rather on the ranking of publication outlets). We used these interviews to verify the present research results 2 years after the initial interviews. All interviews were transcribed verbatim and coded using the software NVivo. Results discussing individual factors concerning open science were published by Scheliga and Friesike (2014).

\section{Emerging trends of open science}

The open science paradigm has just paved the way towards a new division of tasks and a new role understanding within scientific research. New links and forms of collaboration emerged within the science community itself but also between academic research and more application-oriented institutions. The times when research institutes demonstrated intellectual fortresses following the goal of Humboldt's knowledge creation as an end in itself seem to be over in most areas. The complexity of scientific problems and the required investments (time, expertise, and materials) to solve them dramatically increased within the last decades and necessitated the breaking of new grounds in external collaboration (Bozeman and Corley 2004). We identified several trends, which underpin the opening of science:

(1) Research dissemination: from closed journals to open access publications. Many research institutions are opening up their research on open access platforms in order to accelerate knowledge diffusion and with that also knowledge creation. At the world's largest high energy physics lab CERN 3,000 scientists from 174 institutes from 38 countries experiment on a budget of CHF 1 billion with the $27 \mathrm{~km}$ long accelerator (LHC, status 2011). Results are published on the open access platform Atlas Twiki Portal where the estimated 15,000 high energy physics scientists around the globe can read them instantly. In doing so, the high-energy physics community paves the way for new forms of scientific exchange and communication that enable fast peer reviewed publication. The community of high-energy physics is predestined for open access since the community is rather close. In the field of management and economics the opening up of the publication process is slower. Alexandria of the University of St. Gallen has been an early participant in open access, showing a slow start but a rapid acceleration in access statistics in recent years. In contrast to slow and rigid publication procedures of many peer reviewed journals, the Internet-based open platforms offer the possibility to timely make research results available and claim leadership of thought. According to the CERN experience in high-energy physics, the open access initiative accelerated knowledge diffusion by more than a year. When in 2008 the blueprint of the LHC accelerator was published online, thousands of downloads were registered within days. An analysis of citation data showed that free and immediate online dissemination of preprints created an immense citation advantage (Gentil-Beccot and Mele 2009). In many publicly funded research projects the results have to be distributed feely. At 
the Swiss CTI the establishment of a knowledge distribution platform in form of published results is very helpful in order to receive grants. In most EU funded projects the open distribution of knowledge is already a prerequisite to get funding.

Role of research institutes: from ivory towers to knowledge brokers. Traditionally, there was a gap between research driven universities and application driven private companies. This gap is diminishing, as the distribution of tasks between academia and industry changes. The tremendous rise of technology transfer fostered by many universities and private companies further closes the gap between science and practice. For instance, the ETH Zurich and IBM jointly operate the Binnig and Rohrer Nanotechnology Center in Zurich. The center provides a common collaboration platform for researchers of both institutions. As equal collaboration partners, both institutions have the right to publish and to commercialize the jointly created IP. This dual relationship increases the pressure on both partners to timely find applications for the scientific findings generated and to commercialize research results. The local consolidation of many highly dedicated innovation teams proofed to accelerate knowledge creation and opens up fast ways for the commercialization of current results. Additionally, mutual career paths in the ETH and IBM emerged that manifest a liaison management between both entities and create spill-over effects especially with respect to the transfer of tacit knowledge. In recent years, the self-conception of many universities and research institutes changed. Many public institutes moved from being a provider of basic research, towards more application centric research. To enable multiplication on a global scale and to merge competences, various research institutes formed networks that aim at providing direct solutions for business problems. The Auto-ID Labs are a prominent example. They represent a leading global network of academic research laboratories in the field of networked RFID. The labs consist of seven renowned research institutesincluding the MIT Lab, the ETH Zurich Lab, the Cambridge Lab, the Fudan Lab, and the Keio Lab-located on four different continents. The goal of the Auto-ID Labs is to architect the 'Internet of things' and to provide an efficient infrastructure, which facilitates new business models and applications on the basis of the RFID technology.

(3) Outsourcing research: from make to buy. The industrial trend of reducing the value chain activities to focus on core competencies has also affected the relationship between private, application oriented businesses and research institutes. Following this trend, many companies cut their expenses in corporate basic research. As a consequence, numerous firms started to outsource research activities: The elevator company Schindler works together with the Institute of Applied Mathematics at the University of Cologne. On the basis of precise requirements, Schindler outsourced the development of genetic algorithms for its latest elevator control systems. In this regard, the Institute of Applied Mathematics became a knowledge and technology supplier at the very front end of Schindler's innovation process. Daimler outsourced many of the telematics research to several research institutes and universities. ABB outsourced its research on inspection robotics for their installations to a joint venture with the ETH Zurich. SAP has set up several decentralized research labs on campuses of universities, e.g., TU Darmstadt, ETH Zurich, and St.Gallen. Novartis is more and more relying on start-up firms and research institutions to fill the technology pipeline in research and preclinical development. Additionally, the outsourcing of research activities offers SMEs new possibilities to overcome the 'liabilities of smallness' (Gassmann and Keupp 2007). Earlier, due to resource 
constrains, many SMEs were not able to conduct basic research on their own. Thus, outsourcing scientific problems to research institutions allows them to increase their competitive position.

(4) Financing of research: from single-source to multiple-source funding. In recent years, the increasing cost pressure on many public households, led to declining budgets in many public research institutions. Formerly being largely financed by public money, many universities are forced to find additional ways for financing research activities and thus progressively seek third party financing. Various universities increased their activities in technology transfer and in IP commercialization. For example, 25 Bavarian academic institutes formed a patent exploitation network, which is coordinated by a patent bureau. Under the roof of the Fraunhofer Institute, BayernPatent is responsible for the IP commercialization. Additionally, it assists inventors with the filing of patents. Thereby, it works closely with local patent attorneys and offices. BayernPatent covers $100 \%$ of the patent filing and maintenance costs and thus minimizes the risk for the academic institutes. Revenues are split equally between the inventor (25\%), the faculty $(25 \%)$, the university (25\%), and BayernPatent (25\%). Whereas many universities moved from public to more private funding, numerous corporations made an opposite shift. In the 80's roughly $80 \%$ of Siemens' Corporate Technology was financed by uncommitted corporate funds. Today, more than $70 \%$ have to be financed by Corporate Technology on its own responsibility via third party money or business units. This trend is also reflected by several other large firms such as ABB, Daimler, and Philips, which are forced to collaborate with universities and spend seed money in basic research. This supports the universities in their research.

(5) Research culture: from closed disciplinary to open interdisciplinary thinking. For decades, science was predominantly driven by disciplinary research. Within the scientific community, research streams were influenced by few dedicated and topic specific journals. A narrow and disciplinary framing of research articles increased the probability of getting accepted. Additionally, the dogma of 'publish or perish' forced researchers to keep their work secret-at least in the early stage of competition-until submitting it to a scientific journal. This development led to scientific progress but also to disciplinary silos. Within the last decades, the number of interdisciplinary journals grew constantly and new forms of Internet-based collaborations emerged. Offering new ways of publication and collaboration, this development caused a change in thinking towards more open and interdisciplinary research. New scientific cross-links between various research fields offer novel platforms for publication. With this the entire scientific landscape is in constant flux, new research areas emerge and others vanish.

(6) Focus of research: from broad universities to specific institutes. Within the scientific landscape the specialization of research institutes in the public but also private sector increased. The requirement to be more cost efficient forced research activities to be closer related to the core competencies-responsible for value creation and profit generation - of the executing institutes. Within the public sector, specialized researches institutes were formed that attract new researchers as well as private companies. Numerous examples can be found in the sector of environmental technologies in Germany. In the private sector, companies deliberately invest in basic research in strategic fields of major importance. For example, Sulzer Innotec became a specialist for computational fluid dynamics. Later, their know-how in simulation software was applied in the development of a wide variety of products. 
(7) Patents: from stockpiling to patent donation. During the last years, the number of global patent applications of private companies has dramatically increased. Accordingly, firms are confronted with ever growing filing and maintenance costs. Recently, a trend has started: private companies donate patents to research institutions. Many companies reserve the right to license the patent free of charge within their field of business. Doing so, research institutes may use the patent in other fields and leverage knowledge to new areas of application enabling crossindustry innovations. DuPont is a prominent case of a patent donor. The company donated patents amounting to a value of US\$64 million to the Pennsylvania State University and Virginia Tech. The Kellogg Company gave away patents worth US\$49 million to the Michigan State University. Both firms could realize important tax benefits, cost cuttings, and have benefited from positive public relations (Ziegler et al. 2014).

Seeing these trends, it becomes obvious that science is getting increasingly open. As a phenomenon open science moves ahead in revealing new ideas and knowledge freely. Given the different motivational backgrounds between private and public institutions, a symbiotic relationship becomes evident, where research institutions enable research capabilities and private companies contribute commercialization know-how.

\section{Fields defining the future of open science}

Open science is an umbrella term that gets used to describe an array of changes in how scientific research is carried out. Different stakeholders have different opinions on what open science should open. Therefore, the future of this concept lies in several fields. In this section we present those fields that will shape the future of the open science movement:

(1) Higher acceptance of open access. According to a study $89 \%$ of all scientists favor open access journals, but only $8 \%$ actually publish in them (Dallmeier-Tiessen et al. 2010). Despite that "open access journals unchain content and speed up science"stated Mele (director at CERN) - the acceptances of these journals are not equally high in every scientific field. While in medicine and high energy physics open access journals have very high impact factors, their acceptance in the field management research is rather low. However, in all fields we can observe an increasing acceptance and use of open access journals for publishing. How can a higher acceptance of open science be achieved? Respectively, it seems necessary to look at incentives and reward systems for users of open science platforms that go beyond reputational aspects (Scheliga and Friesike 2014).

(2) Open reviewing and new measurements. As the UK Parliamentary Office of Science and Technology put it (2002), peer review "is an inherently conservative process ... [that] ... encourages the emergence of self-serving cliques of reviewers, who are more likely to review each others' grant proposals and publications favorably than those submitted by researchers from outside the group. New ways of complementary measuring scientific output are needed. There is a need to develop a system of scientific impact 2.0". Despite this apparent critique, initiatives to open up the review process are suffering from acceptance. In June 2006, Nature launched an experiment in opening up the peer review process. A number of articles, which had been submitted to the regular review process, were also made available for an open online review. Only $5 \%$ of the authors agreed to participate in the experiment, and 
half of those articles (46\%) did not even receive a single comment. More research is required to fully understand why researchers are reluctant to open review processes and which measures are necessary to improve its acceptance. Today's measurement of scientific impact is mostly based on journal impact factors. This measurement is rather slow, closed, and biased by social group effects. A key factor to establish new measurements for scientific impact could be played by services that publish individual user measures (e.g., Research Gate or Google Scholar). Here different impact measurements are opened up to the public: e.g., average number of citations per paper and per author, Hirsch's h-index and related parameters, Zhang's e-index, Egghe's g-index as well as age-weighted citation rate, or Research Gates own RG Score. The often seen isolation of peer-reviewed journals from practice and society could be overcome by the diffusion of research results in social media. Here, research can be addressed, commented, and better marketed. Publications could be selected and evaluated by interested readers. Social media already plays a prominent role in the altmetrics discussion, however more empirical evidence is needed (Priem et al. 2012; Piwowar 2013).

(3) Virtual knowledge creation. With the use of the Internet, new forms of sharing and generating knowledge came to light that led to new challenges: how can collectivly generated knowledge be published? What are guiding frames concerning plagiarism? How should plagiarism be handled? In the Anglo-Saxon dominated science landscape, each researcher is evaluated based on his or her individual scientific contribution. This requires that a clear assignment of contribution is possible. The collaborative knowledge creation in virtual networks-often described as E-Science-challenges this dogma as a precise identification of individual researchers and their work is often not possible. New solutions are required regarding the assignment problem in case several authors work on one contribution.

(4) Quality assurance of scientific content. The successful opening of science presupposes explicit measures for quality assurance with respect to content. Considering the rise of open science platforms, decisions about user authorizations and access rights have to be made. In many cases regular citizens help to investigate scientific problems (Franzoni and Sauermann 2014). These researchers have no scientific background, which imposes new challenges for research management. How do new forms of evaluation and review systems that secure rigorousness of research look like? Transparency seems to be key. The comprehensibility of the entire research process-from the very first idea to the final results-is crucial for the quality assurance of crowd science projects. An open question remains regarding the choice of a platform: which one is the right one for which project?

(5) Accelerating interdisciplinary science. Based on open science platforms, unrestricted navigation across different subject areas and scientific disciplines is possible. It leads to new ways of reviewing existing knowledge. What is the impact of new search and language processing technologies on the creation of new interdisciplinary insights?

(6) Outsourcing research by SMEs. Within an economy, SMEs present the largest number of companies. The effect of open science on research collaborations of SMEs leaves room for further investigations (van de Vrande et al. 2009): what are success factors? How are collaboration processes characterized? What are relevant intermediaries and platforms for the matchmaking between research and SMEs?

(7) IP trade. As outlined before, the tradability of knowledge in form of IP is a catalyst for opening up science. Yet, the determinants of successful trade are not investigated 
sufficiently. Patent valuation remains a challenge, as most patent transactions are not publicly disclosed. Efficient market places for IP might lead to more open approaches in research, as they will give more guidance in patent valuation. Furthermore, possible negative consequences of an open trade of IP-e.g., effects of patent trolls on value creation-have to be investigated in more detail. How can IP be made more tradable?

\subsection{Concluding remarks}

Overall it becomes evident, that the proponents of open science strive for an improved scientific system. They want the scientific system to create better results, to make its outcomes accessible to anyone, and to foster collaboration among all interested parties. To this end one can argue that open science describes an irreversible paradigm shift at the very front of the innovation funnel. However, many concepts presented in the realm of open science lack clear incentives on the individual level. The advantages for the system as a whole are clearly communicated and convincing. Yet, it remains to be seen whether these advantages are sufficient to motivate individual researchers to pursue more open science. An open science research system does not only improve academic research but holds tremendous potential for industrial applications. Here, we need to learn more on how this interaction can be supported and managed. At large, current scientific contributions are still fragmented and are far away from presenting a holistic picture of open science. Many knowledge gaps within various fields are evident. Clear policy implications are needed to address the issue of individual incentives for scientists. The promising idea of open science comes with a multitude of possible challenges, which need to be addressed in order to make this research paradigm work. The field of open science is still at an early stage and offers a wide field for future research. We invite researchers to contribute to this fascinating area and to help answering the many remaining questions.

\subsection{Limitations}

Given our research design it is helpful to point out several limitations. Firstly, as typical for qualitative research, our study describes a present phenomenon. But we are unable to quantify it. We are unable to provide insights on how 'open' research actually is and how many researchers are engaged in open science. Secondly, this study provides a general overview on this rather young occurrence. We do not compare disciplines or highlight promoting and hindering factors that would explain why certain disciplines are engaging in open science more vividly than others. Thirdly, we do not look at individual drivers. The idea of open science and its key argument (making research processes as transparent and open as possible) is good for society as a whole; yet it does not take into consideration the individual researcher. In many cases what is good for society is not in the best interest of the researcher himself. Career incentives and institutional policies might hinder open science. Fourthly, our data emphasizes the German speaking research and business community. To minimize local bias and ensure global validity, we interviewed managers and researchers with an international background. Practically, we selected researchers that previously published in international journals and manager that work in a global business environment to ensure that the findings are valid beyond the German-speaking world. 
Open Access This article is distributed under the terms of the Creative Commons Attribution License which permits any use, distribution, and reproduction in any medium, provided the original author(s) and the source are credited.

\section{References}

Bartling, S., \& Friesike, S. (2014). Opening science: The evolving guide on how the internet is changing research, collaboration and scholarly publishing. Cham: Springer.

Bilgram, V., Brem, A., \& Voigt, K.-I. (2008). User-centric innovations in new product developmentSystematic identification of lead users harnessing interactive and collaborative online-tools. International Journal of Innovation Management, 12(3), 419-458.

Björk, B.-C., \& Solomon, D. (2013). The publishing delay in scholarly peer-reviewed journals. Journal of Informetrics, 7(4), 914-923.

Bozeman, B., \& Corley, E. (2004). Scientists' collaboration strategies: Implications for scientific and technical human capital. Research Policy, 33(4), 599-616.

Braun, A., Gomez, I., Mendez, A., \& Schubert, A. (1992). International co-authorship patterns in physics and its subfields, 1981-1985. Scientometrics, 24(2), 181-200.

Bullinger, A. C., Neyer, A.-K., Rass, M., \& Moeslein, K. M. (2010). Community-based innovation contests: Where competition meets cooperation. Creativity and Innovation Management, 19(3), 290-303.

Chesbrough, H. W. (2003a). Open innovation: The new imperative for creating and profiting from technology. Boston: Harvard Business School Press.

Chesbrough, H. W. (2003b). The era of open innovation. MIT Sloan Management Review, 44(3), 35-41.

Chesbrough, H. W. (2006). Open business models: How to thrive in the new innovation landscape. Cambridge, MA: Harvard Business School Publishing.

Christensen, J. F., Olesen, M. H., \& Kjær, J. S. (2005). The industrial dynamics of open innovationEvidence from the transformation of consumer electronics. Research Policy, 34(10), 1533-1549.

Cohen, W. M., Nelson, R. R., \& Walsh, J. P. (2000). Protecting their intellectual assets: appropriability conditions and why U.S. manufacturing firms patent (or not). NBER Working Paper 7552.

Dahlander, L., Fredriksen, L., \& Rullani, F. (2008). Online communities and open innovation: Governance and symbolic value creation. Industry and Innovation, 15(2), 115-123.

Dahlander, L., \& Gann, D. M. (2010). How open is innovation? Research Policy, 39(6), 600-709.

Dallmeier-Tiessen, S., Darby, R., Goerner, B., Hyppoelae, J., Igo-Kemenes, P., Kahn, D., Lambert, S., Lengenfelder, A., Leonard, C., Mele, S., Polydoratou, P., Ross, D., Ruiz-Perez, S., Schimmer, R., Swaisland, M., \& van der Stelt, W. (2010). First results of the SOAP project. Open access publishing in 2010, working paper. http://arxiv.org/abs/1010.0506v1

De Roure, D., Goble, C., Aleksejevs, S., Bechhofer, S., \& Bhagat, J. (2010). Towards open science: the myExperiment approach. Concurrency and Computation: Practice and Experience, 22, 2335-2353.

Eisenhardt, K. (1989). Building Theories from Case Study Research. Academy of Management Review, 14(4), 532-550.

Fisher, B. S., Cobane, C. T., Vander Ven, T. M., \& Cullen, F. T. (1998). How many authors does it take to publish an article? Trends and patterns in political science. PS. Political Science and Politics, 31(4), $847-856$.

Franke, N., von Hippel, E., \& Schreier, M. (2006). Finding commercially attractive user innovations: A test of lead user theory. Journal of Product Innovation Management, 23(4), 301-315.

Franzoni, C., \& Sauermann, H. (2014). Crowd science: The organization of scientific research in open collaborative projects. Research Policy, 43(1), 1-20.

Gassmann, O., \& Enkel, E. (2004). Towards a theory of open innovation: Three core process archetypes. Proceedings of the R\&D Management Conference, Lisbon, Portugal, 6-9 July.

Gassmann, O., Kausch, C., \& Enkel, E. (2010). Negative side effects of customer integration. International Journal of Technology Management, 50(1), 43-63.

Gassmann, O., \& Keupp, M. M. (2007). The internationalisation of research and development in Swiss and German born globals: Survey and case study evidence. International Journal of Entrepreneurship and Small Business, 4(3), 214-233.

Gentil-Beccot, A., \& Mele, S. (2009). Citing and reading behaviours in high-energy physics. How a community stopped worrying about journals and learned to love repositories. http://arxiv.org/abs/0906. 5418

Gowers, T., \& Nielsen, M. (2009). Massively collaborative mathematics. Nature, 461, 879-881. 
Grand, A., Wilkinson, C., Bultitude, K., \& Winfield, A. F. T. (2012). Open Science: A New, “Trust Technology"? Science Communication, 34, 679-689.

Haeussler, C. (2011). Information-sharing in academia and the industry: A comparative study. Research Policy, 40(1), 105-122.

Hagedoorn, J. (1993). Understanding the rationale of strategic technology partnering: Inter-organizational modes of cooperation and sectoral differences. Strategic Management Journal, 14(5), 371-385.

Hagedoorn, J. (2002). Inter-firm R\&D partnerships: An overview of major trends and patterns 1960. Research Policy, 31(4), 477-492.

Hagström, W. O. (1965). The scientific community. New York: Basic Books.

Herstatt, C., \& Kalogerakis, K. (2005). How to use analogies for breakthrough innovations. International Journal of Innovation and Technology Management, 27(3), 418-436.

Herzog, P. (2011). Open and closed innovation: Different cultures for different strategies. Wiesbaden: Gabler Verlag.

Hicks, D. (1995). Published papers, tacit competencies and corporate management of the public/private character of knowledge. Industrial and Corporate Change, 4(2), 401-424.

Howells, J. (2006). Intermediation and the role of intermediaries in innovation. Research Policy, 35(5), 715-728.

Howells, J. (2008). New directions in R\&D: Current and prospective challenges. R\&D Management, 38(3), 241-252.

Hunter, L., \& Leahey, E. (2008). Collaborative research in sociology: Trends and contributing factors. The American Sociologist, 39(4), 290-306.

Jong, S., \& Slavova, K. (2014). When publications lead to products: The open science conundrum in new product development. Research Policy, 43(4), 645-654.

Katz, R., \& Allen, T. J. (1982). Investigating the not invented here (NIH) syndrome: A look at the performance, tenure, and communication patterns of $50 \mathrm{R} \& \mathrm{D}$ project groups. $R \& D$ Management, 12(1), 7-19.

Kim, W. C., \& Mauborgne, R. (2004). Blue ocean strategy. Harvard Business Review, 82(10), 76-84.

Kodama, F. (1992). Technology fusion and the new Research-and-Development. Harvard Business Review, 70(4), 70-78.

Koen, P., Ajamian, G., Burkart, R., Clamen, A., et al. (2001). Providing clarity and a common language to the "Fuzzy Front End". Research and Technology Management, 44(2), 46-55.

Kuhn, T. (1962). Structure of scientific revolutions. Chicago: University of Chicago Press.

Lievrouw, L. A. (2010). Social media and the production of knowledge: A return to little science? Social Epistemology, 24, 219-237.

Luethje, C. (2004). Characteristics of innovating users in a consumer goods field-An empirical study of sports-related consumers. Technovation, 23(9), 683-695.

Maske, K. L., Durden, G. C., \& Gaynor, P. E. (2003). Determinants of scholarly productivity among male and female economists. Economic Inquiry, 41(4), 555-564.

McCain, K. (1991). Communication, competition, and secrecy: The production and dissemination of research-related information in genetics. Science, Technology and Human Values, 16, 491-516.

Merton, R. K. (1973). The sociology of science: Theoretical and empirical investigations. Chicago: University of Chicago Press.

Meyer, E. T., \& Schroeder, R. (2013). Digital Transformations of Scholarship and Knowledge. In W. H. Dutton (Ed.), The Oxford handbook of internet studies (pp. 307-327). Oxford: Oxford University Press.

Mukherjee, A., \& Stern, S. (2009). Disclosure or secrecy? The dynamics of open science. International Journal of Industrial Organization, 27, 449-462.

Murray, F. (2006). The oncomouse that roared: Hybrid exchange strategies as a source of productive tension at the boundary of overlapping institutions. MIT Sloan School of Management Working Paper.

Nambisan, S., \& Baron, R. A. (2010). Different roles, different strokes: Organizing virtual customer environments to promote two types of customer contributions. Organization Science, 21(2), 554-572.

Neylon, C., \& Wu, S. (2009). Open science: Tools, approaches, and implications. Pacific Symposium on Biocomputing, 14, 540-544.

Nielsen, M. (2011). An informal definition of open science. The OpenScience Project. http://www. openscience.org/blog/?p=454

Nielsen, M. (2012). Reinventing discovery: The new era of networked science. Princeton, NJ: Princeton University Press.

Parliamentary Office of Science and Technology. (2002). Postnote-Peer review, (182), 1-4. http://www. parliament.uk/documents/post/pn182.pdf. 
Pike, T. W. (2010). Collaboration networks and scientific impact among behavioral ecologists. Behavioral Ecology, 21(2), 431-435.

Piller, F. T., \& Walcher, D. (2006). Toolkits for idea competitions: A novel method to integrate users in new product development. R\&D Management, 36(3), 307-318.

Pisano, G. (2006). Profiting from innovation and the intellectual property revolution. Research Policy, 35(8), 1122-1130.

Piwowar, H. A. (2013). Altmetrics: Value all research products. Nature, 493, 159.

Powell, W. W., White, D. R., Koput, K. W., \& Owen-Smith, J. (2005). Network dynamics and field evolution: The growth of interorganizational collaboration in the life sciences. American Journal of Sociology, 110, 1132-1205.

Priem, J., Piwowar, H. A., \& Hemminger, B. M. (2012). Altmetrics in the wild: Using social media to explore scholarly impact. http://arxiv.org/abs/1203.4745.

Procter, R., Williams, R., Stewart, J., Poschen, M., \& Snee, H. (2010). Adoption and use of Web 2.0 in scholarly communications. Philosophical Transactions of the Royal Society A: Mathematical, Physical and Engineering Sciences, 368, 4039-4056.

Reitzig, M., Henkel, J., \& Heath, C. (2007). On sharks, trolls, and their patent prey-Unrealistic damage awards and firms' strategies of "being infringed". Research Policy, 36(1), 134-154.

Rhoten, D., \& Powell, W. W. (2007). The frontiers of intellectual property: Expanded protection vs. new models of open science. Annual Review of Law and Social Science, 3, 345-373.

Scheliga, K., \& Friesike, S. (2014). Putting open science into practice: A social dilemma? First Monday, 19, 9.

Schildhauer, T. (2011). Open Innovation und digitale Kommunikation - Vier Thesen zum Aufbruch in neue und unbekannte Welten. In T. Schildhauer, N. Tropisch, \& C. Busch (Eds.), Magie und Realität des Heldenprinzips heute (pp. 152-157). Münster: Verlagshaus Monsenstein und Vannerdat.

Sieg, J. H., Wallin, M. W., \& von Krogh, G. (2010). Managerial challenges in open innovation: A study of innovation intermediation in the chemical industry. R\&D Management, 40(3), 281-291.

Stephan, P. E. (1996). The economics of science. Journal of Economic Literature, 34, 1199-1235.

Tacke, O. (2010) Open science 2.0: how research and education can benefit from open innovation and web 2.0. 1. Symposium on Collective Intelligence (COLLIN 2010).

Thursby, M., Thursby, J., Haeussler, C., and Jiang, L. (2009) Do academic scientists freely share information? Not necessarily. Vox News 29 Nov. 2009.

Vallas, S. P., \& Kleinman, D. L. (2008). Contradiction, convergence and the knowledge economy: The confluence of academic and industrial biotechnology. Socio-Economic Review, 6(2), 283-311.

van de Vrande, V., de Jong, J. P. J., Vanhaverbeke, W., \& de Rochemont, M. (2009). Open innovation in SMEs: Trends, motives and management challenges. Technovation, 29(6-7), 423-437.

van de Vrande, V., Vanhaverbeke, W., \& Gassmann, O. (2010). Broadening the scope of open innovation: Past research, current research and future directions. International Journal of Technology Management, 52(3-4), 221-235.

von Hippel, E. (1986). Lead users: A source of novel product concepts. Management Science, 32(7), 791-805.

von Hippel, E., \& von Krogh, G. (2006). Free revealing and the private collective model for innovation incentives. $R \& D$ Management, 36(3), 295-306.

Von Krogh, G., \& von Hippel, E. (2003). Open source software: Introduction. Research Policy, 32(7), $1149-1157$.

Waldrop, M. M. (2008) Science 2.0: Great New Tool, or Great Risk? Scientific American. http://www. scientificamerican.com/article.cfm?id=science-2-point-0-great-new-tool-or-great-risk

West, J., \& Lakhani, K. R. (2008). Getting clear about communities in open innovation. Industry \& Innovation, 15(2), 223-231.

Ziegler, N., Gassmann, O., \& Friesike, S. (2014). Why do firms give away their patents for free? World Patent Information, 37, 19-25. 